\title{
Spirochaeta isovalerica sp. nov., a Marine Anaerobe That Forms Branched-Chain Fatty Acids as Fermentation Products
}

\author{
C. S. HARWOOD ${ }^{\dagger}$ AND E. CANALE-PAROLA* \\ Department of Microbiology, University of Massachusetts, Amherst, Massachusetts 01003
}

\begin{abstract}
Four strains of obligately anaerobic spirochetes were isolated from marine intertidal mud. These strains grew to yields of $2 \times 10^{8}$ to $6 \times 10^{8}$ cells per $\mathrm{ml}$ in chemically defined media containing glucose, amino acids or $\mathrm{NH}_{4} \mathrm{Cl}$, sulfide, vitamins, and inorganic salts. These spirochetes required relatively high levels of $\mathrm{Na}^{+}$for growth and utilized carbohydrates but not amino acids as growth substrates. Glucose was fermented to $\mathrm{CO}_{2}, \mathrm{H}_{2}$, ethanol, and acetate. These four strains also formed the branched-chain fatty acids isovalerate, 2-methylbutyrate, and isobutyrate as fermentation products of L-leucine, L-isoleucine, and L-valine, respectively. The adenosine 5'-triphosphate generated via fermentation of these amino acids was expended by the spirochetes to prolong survival during periods of growth substrate starvation. The deoxyribonucleic acids of the four strains contained 63.6 to $65.6 \mathrm{~mol} \%$ guanine plus cytosine. We concluded that these four strains are representatives of a new species, for which we propose the name Spirochaeta isovalerica; the type strain of this species is strain MA-2 (= DSM 2461).
\end{abstract}

Spirochetes are frequently observed in samples of anoxic mud collected from freshwater and saltwater environments. The obligately and facultatively anaerobic spirochetes present in salt marsh habitats have been enumerated by using rifampin as a selective agent, and these organisms have been found to be present at densities ranging from $10^{4}$ to $10^{6}$ colony-forming units per $\mathrm{g}$ (wet weight) of sediment (19). Although significant numbers of spirochetes are present in marine sediments, few marine species have been described. We isolated 14 strains of spirochetes from intertidal muds collected in Pacific and Atlantic coastal regions and examined these isolates for selected ultrastructural and metabolic properties. In the course of these studies we identified four strains of obligately anaerobic spirochetes that formed the four- and five-carbon branched-chain fatty acids isovalerate, 2-methylbutyrate, and isobutyrate as minor fermentation products. These fermentation products are not formed by the other marine spirochetes that have been described and have not been reported for any of the recognized species of free-living terrestrial spirochetes (4).

In previous papers we have described the results of studies carried out to elucidate the significance of branched-chain fatty acid formation by one of the four spirochete strains (strain MA- $2^{\mathrm{T}}$ [type strain]) (9-11). We determined that

† Present address: Department of Biology, Yale University, New Haven, CT 06511. the above-mentioned branched-chain fatty acids are derived from fermentation of L-leucine, $\mathrm{L}$ isoleucine, and L-valine. Although these amino acids do not serve as growth substrates for the spirochetes, the dissimilation of these compounds provides the organisms with maintenance energy for cell functions not related to growth. Thus, spirochete strain MA- $2^{\mathrm{T}}$ catabolizes branched-chain amino acids as a strategy to prolong survival when fermentable carbohydrates or other growth substrates are not available in its natural environment.

In this paper we present a morphological and physiological characterization of the four spirochete strains that form branched-chain fatty acids. Our results indicate that these isolates represent a previously undescribed species of bacteria, for which we propose the name Spirochaeta isovalerica.

\section{MATERIALS AND METHODS}

Bacterial strains. $S$. isovalerica strains MA-2 ${ }^{\mathrm{T}}$, WH2, MA-3, and RB-2 were isolated from black, viscous, sulfide-rich mud collected from a marshy area located in Woods Hole, Mass. This marshy area has been described previously (1). Strains $\mathrm{MA}-2^{\mathrm{T}}$ and MA-3 were isolated by a method that involved migration of the spirochetes through an agar medium under anaerobic conditions. We have described the procedure used to isolate $S$. isovalerica strain $\mathrm{MA}-2^{\mathrm{T}}$ previously (9). The same procedure was used to isolate strain MA-3, except that the isolation medium was supplemented with a final concentration of $0.025 \%(\mathrm{wt} / \mathrm{vol})$ cellobiose. Strain WH-2 was isolated by a method that took 
advantage of the ability of spirochetes to pass through the pores of membrane filters (6). The medium used for the isolation of strain WH-2 contained $0.2 \mathrm{~g}$ of cellobiose, $0.1 \mathrm{~g}$ of Trypticase (BBL Microbiology Systems, Cockeysville, Md.), $0.1 \mathrm{~g}$ of yeast extract (Difco Laboratories, Detroit, Mich.), $0.05 \mathrm{~g}$ of $\mathrm{L}-$ cysteine hydrochloride, $0.1 \mathrm{ml}$ of resazurin $(0.1 \%, \mathrm{wt} /$ vol), $0.01 \mathrm{M}$ tris(hydroxymethyl)aminomethane hy-

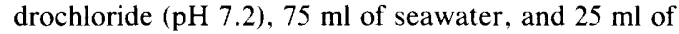
distilled water. Pure cultures of spirochete strain WH2 were obtained by repeated serial dilution of isolated colonies in tubes of isolation medium that contained $0.8 \mathrm{~g}$ of agar (Difco) per $100 \mathrm{ml}$. Strain RB-2 was isolated by Blakemore and Canale-Parola by the same procedure used to isolate strain MA-3.

Media and growth conditions. $S$. isovalerica strains were routinely cultivated anaerobically in a prereduced complex marine medium (MSM broth) that contained yeast extract, peptone, Trypticase, and glucose and was prepared in artificial seawater (9). Cells were also grown and maintained in agar deeps of a marine glucose-Trypticase-yeast extract medium (MGTY medium) (9). This medium was prepared as described previously (9), except that it included $5 \mathrm{ml}$ of $1 \mathrm{M}$ tris(hydroxymethyl)aminomethane hydrochloride buffer per $100 \mathrm{ml}$ rather than $5 \mathrm{ml}$ of $50 \mathrm{mM}$ tris(hydroxymethyl)aminomethane hydrochloride buffer per $100 \mathrm{ml}$. For nutritional studies, $S$. isovalerica strains were grown in a defined medium (MMM broth) that contained glucose, L-asparagine, cysteine, vitamins, and inorganic salts and was prepared in artificial seawater (9). The abilities of strains to utilize various carbon compounds for growth were determined by subculturing growing cells for three transfers into MMM broth to which potential substrates had been added in place of glucose. Each potential substrate was filter-sterilized separately, and most were added to final concentrations of $0.2 \%$ (wt/vol); L-valine, L-isoleucine, L-leucine, L-proline, glycine, sodium succinate, sodium pyruvate, sodium 2-ketoglutarate, lithium lactate, and Tween 80 were added to final concentrations of $0.1 \%(\mathrm{wt} / \mathrm{vol})$. Potassium acetate was added to a final concentration of $0.02 \%$ (wt/vol), and ball-milled cellulose was added to a final concentration of $0.6 \%(\mathrm{wt} / \mathrm{vol})$. Xylan and starch were washed three times in $70 \%$ ethanol to remove contaminating low-molecular-weight sugars before filter sterilization. A 5-ml amount of the amino acid mixture (12) used in nutritional studies was added per $100 \mathrm{ml}$ of MMM medium. This mixture differed from the mixture described previously (12) in that L-leucine, L-isoleucine, and L-valine were added separately to final concentrations of $0.1 \%(\mathrm{wt} / \mathrm{vol})$.

The abilities of spirochetes to utilize various nitrogen sources for growth were determined as described previously (9).

$S$. isovalerica strains were maintained by incubating stab cultures in MGTY medium at $15^{\circ} \mathrm{C}$, a temperature at which slow growth occurred. Cultures were transferred every 8 days.

Analysis of fermentation products. The volatile and nonvolatile fatty acids and branched-chain alcohols produced by growing cells were determined by gasliquid chromatography, as described previously (9). Gaseous and other nongaseous fermentation products were determined by techniques described previously (9).
Microscopy. The cells used for phase-contrast microscopy and electron microscopy were grown in MSM broth and were taken from cultures in the exponential phase of growth. The equipment and methods used for light microscopy and photography have been described previously (7). Negatively stained specimens for electron microscopy were prepared and examined as described by Paster and Canale-Parola (16), except that cells were stained with $1.0 \%(\mathrm{wt} / \mathrm{vol})$ phosphotungstic acid $(\mathrm{pH} 5.5)$ for $5 \mathrm{~s}$.

Determination of $\mathbf{G}+\mathbf{C}$ contents of DNAs. The deoxyribonucleic acid (DNA) was purified from each $S$. isovalerica strain as described by Breznak and CanaleParola (2), with the following modification. After cells were lysed by adding lysozyme and sodium lauryl sulfate, the cell lysate was incubated at $46^{\circ} \mathrm{C}$ for $2 \mathrm{~h}$ with protease (Sigma Chemical Co., St. Louis, Mo.) at a final concentration of $1 \mathrm{mg} / \mathrm{ml}$ of lysate. The purified DNA was dissolved in $0.1 \times \mathrm{SSC}(1 \times \mathrm{SSC}$ is $0.15 \mathrm{M}$ $\mathrm{NaCl}$ plus $0.015 \mathrm{M}$ sodium citrate) and then dialyzed extensively against $0.1 \times \mathrm{SSC}$. The guanine-plus-cytosine $(\mathrm{G}+\mathrm{C})$ content of the DNA was determined from its thermal denaturation temperature (15). DNA isolated from Escherichia coli K-12 strain ATCC e23716 was used as a control $(\mathrm{G}+\mathrm{C}$ content, $51.4 \mathrm{~mol} \%)$.

Enzyme activities. Phosphofructokinase (EC 2.7.1.11), fructose diphosphate aldolase (EC 4.1.2.13), glyceraldehyde phosphate dehydrogenase (EC 1.2.1.12), glucose-6-phosphate dehydrogenase (EC 1.1.1.49), and phosphogluconate dehydrogenase (EC 1.1.1.43) activities were assayed by linking the reactions to pyridine nucleotide reduction, as previously described (13). 6 Phosphogluconate dehydratase (EC 4.2.1.12) and 2keto-3-deoxy-6-phosphogluconate aldolase (EC 4.2.1.14) activities were assayed jointly by measuring the production of pyruvate from 6-phosphogluconate. Each assay mixture $(0.5 \mathrm{ml})$ contained $0.2 \mathrm{M}$ tris(hydroxymethyl)aminomethane buffer ( $\mathrm{pH} 8.5$ ), $0.01 \mathrm{M}$ $\mathrm{MgSO}_{4}, 1.0 \mathrm{mM}$ 6-phosphogluconate, and cell extract. The reaction mixtures were incubated for $30 \mathrm{~min}$ at $30^{\circ} \mathrm{C}$, and then the reactions were terminated by adding $0.5 \mathrm{ml}$ of $0.02 \%$ (wt/vol) dinitrophenylhydrazine in $5 \mathrm{~N} \mathrm{HCl}$. After $10 \mathrm{~min}$ of incubation at room temperature, $1.0 \mathrm{ml}$ of $2 \mathrm{~N} \mathrm{NaOH}$ was added, and the dinitrophenylhydrazone of pyruvate was determined at $450 \mathrm{~nm}$. The amino acid aminotransferase, 2-keto acid oxidoreductase, phosphate acyltransferase, and fatty acid kinase activities utilized by cells during fermentation of branched-chain amino acids were determined as described previously (10).

The cell extracts used in enzyme assays were prepared as described previously (10).

Other experimental procedures. Tests for catalase, oxidase, and nitrite formation from nitrate were performed as described by Smibert and Krieg (18). Pseudomonas cepacia was used as a catalase-positive and oxidase-positive control.

\section{RESULTS}

Morphology and growth characteristics. The cells of $S$. isovalerica strains MA-2 ${ }^{\mathrm{T}}$, WH-2, RB2 , and MA-3 were helical and measured 0.4 by 10 to $15 \mu \mathrm{m}$ during growth in MSM broth (Fig. 1). Shorter and longer cells $(6$ to $50 \mu \mathrm{m}$ ) were also observed. The average cell length increased 


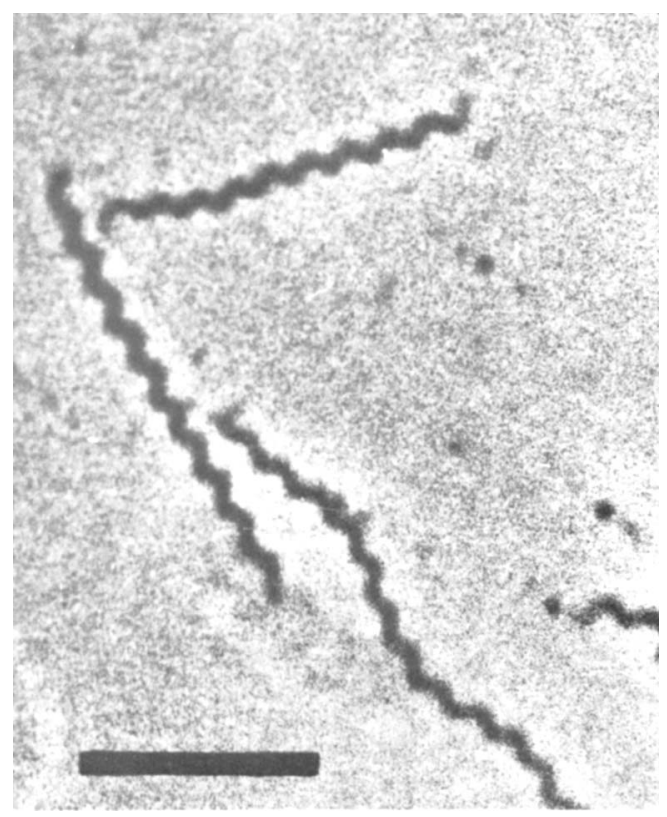

FIG. 1. Phase-contrast photomicrograph of $S$. isovalerica $\mathrm{MA}-2^{\mathrm{T}}$ (wet mount preparation). Bar $=5 \mu \mathrm{m}$.

in late logarithmic and stationary growth phases. The cells were tightly coiled and the coils had a wavelength of $1.0 \mu \mathrm{m}$ and an amplitude of 0.6 $\mu \mathrm{m}$. The coiling of the cells was regular, and usually the cells did not exhibit secondary coiling (5). The cells of the four $S$. isovalerica strains performed the translational movement characteristic of spirochetes (5) and occasionally were observed creeping or crawling on the surfaces of glass microscope slides. In broth cultures the cells were actively motile in the early logarithmic phase of growth, but the percentages of motile cells decreased as the ages of the cultures increased. The cells tended to sediment and collect in the bottoms of culture tubes during the late exponential and stationary phases of growth in broth. When growing in defined medium (MMM broth), cells of $S$. isovalerica MA-3 and WH-2 tended to clump and stick to the sides of culture tubes, forming a white film, although a significant proportion of the cells remained suspended in the medium. Spherical bodies similar in morphology to those formed by other spirochetes (2) were present in stationary-phase or old cultures of the $S$. isovalerica strains.

Electron microscopy of the $S$. isovalerica strains revealed morphological features typical of spirochetes $(4,5)$. Two periplasmic fibrils were present per cell, one inserted near one end of the protoplasmic cylinder and the other inserted near the opposite end. The periplasmic fibrils were inserted subterminally by means of disk-shaped structures (insertion disks) and over-lapped in the central portion of the cell. An outer sheath surrounded both periplasmic fibrils and the protoplasmic cylinder (Fig. 2).

The $S$. isovalerica strains grew only anaerobically. Colonies in MGTY agar deeps were spherical with diffuse edges and white, resembling cotton balls in appearance. The colonies measured 2 to $4 \mathrm{~mm}$ in diameter after 2 days of growth at $30^{\circ} \mathrm{C}$, but varied in size depending on the number per culture tube and the length of incubation. In MSM broth at $30^{\circ} \mathrm{C}$ the yields of $S$. isovalerica strains $\mathrm{WH}-2, \mathrm{RB}-2$, and $\mathrm{MA}-2^{\mathrm{T}}$ were $8 \times 10^{8}$ to $9 \times 10^{8}$ cells per ml. These strains had average doubling times of $3.5 \mathrm{~h} . S$. isovalerica MA-3 grew to a yield of $6 \times 10^{8}$ cells per $\mathrm{ml}$ in MSM broth and had a doubling time of approximately $8.5 \mathrm{~h}$. The shortest generation times and highest yields of $S$. isovalerica strains were at $30^{\circ} \mathrm{C}$. The cell yields and growth rates, as estimated by visual inspection of growth in stab cultures in MGTY medium, were lower at 15 and $35^{\circ} \mathrm{C}$. $S$. isovalerica strains $\mathrm{MA}-2^{\mathrm{T}}$, WH2 , and RB-2 grew very slightly at $5^{\circ} \mathrm{C}$ in MGTY agar stabs, whereas strain MA-3 did not grow at this temperature. All four $S$. isovalerica strains grew very poorly or not at all at $39^{\circ} \mathrm{C}$.

The $S$. isovalerica strains were gram negative, catalase negative, and oxidase negative. They did not reduce nitrate to nitrite.

Nutrition. The $S$. isovalerica strains grew in a chemically defined medium (MMM broth) containing D-glucose as the fermentable substrate, $\mathrm{L}$-cysteine as the reducing agent, $\mathrm{L}$-asparagine as a nitrogen source, vitamins, and inorganic salts (9). The yields in this medium were $5 \times 10^{8}$ to 6 $\times 10^{8}$ cells per ml for strains $\mathrm{MA}-2^{\mathrm{T}}$, WH-2, and RB-2 and $2.8 \times 10^{8}$ cells per ml for strain MA-3. The $S$. isovalerica strains did not require vitamins for growth, although growth was stimulated by the inclusion of a vitamin (growth factor) mixture in MMM medium. In MMM medium which lacked the growth factor mixture the yields ranged from $0.5 \times 10^{8}$ to $1.0 \times 10^{8}$ cells per ml.

The ability of strain MA- $2^{\mathrm{T}}$ to utilize various nitrogen sources for growth was tested in MMM medium lacking L-asparagine but containing $\mathrm{Na}_{2} \mathrm{~S}$ instead of cysteine. This medium yielded 5 $\times 10^{8}$ to $6 \times 10^{8}$ strain MA-2 ${ }^{\mathrm{T}}$ cells per ml when it contained L-leucine, $\mathrm{L}$-isoleucine, and L-valine as sole sources of nitrogen. These branchedchain amino acids also served as nitrogen sources but supported lower yields (9) when they were supplied singly to the spirochete. LAsparagine, L-glutamic acid, and ammonium chloride served as sole nitrogen sources for strain MA-2 ${ }^{\mathrm{T}}$ and yielded $5.1 \times 10^{8}, 3.3 \times 10^{8}$, and $2.4 \times 10^{8}$ cells per ml, respectively.

The $S$. isovalerica strains did not grow in 
MMM broth lacking glucose. D-Fructose, Dmannose, D-galactose, D-xylose, cellobiose, sucrose, trehalose, maltose, L-rhamnose, L-fucose, D-mannitol, and soluble starch each supported growth of all $S$. isovalerica strains when it replaced glucose in MMM broth. Some of the $S$. isovalerica strains grew slightly when $\mathrm{L}$-arabinose, D-arabinose, or D-ribose was used as the carbon and energy source. Xylan supported growth of all $S$. isovalerica strains except strain MA-3 when it replaced glucose in MMM broth. Lactose, D-sorbitol, D-ribitol, D-galacturonic acid, raffinose, inulin, cellulose, and Tween 80 did not serve as growth substrates for any of the $S$. isovalerica strains. A mixture of 19 amino acids (see above) did not support growth of the $S$. isovalerica strains. Furthermore, $\mathrm{L}$ valine, L-isoleucine, L-leucine, glycine, and $\mathrm{L}$ proline did not serve as growth substrates when they were present either singly or in combinations in glucose-free MMM medium. All $S$. isovalerica strains also failed to utilize fumarate, 2-ketoglutarate, lactate, succinate, and acetate for growth, even when these compounds were present together with branched-chain amino acids in defined medium. $S$. isovalerica RB-2 grew slightly, whereas strains $\mathrm{MA}^{2}{ }^{\mathrm{T}}, \mathrm{MA}-3$, and WH-2 did not, when pyruvate was supplied as the sole carbon and energy source in MMM medium which lacked glucose. The growth of strain RB-2 was not stimulated when pyruvate was supplied in combination with leucine, isoleucine, and valine. These data indicate that $S$. isovalerica is primarily a saccharolytic species and that it lacks the ability to use most compounds other than carbohydrates as growth substrates. In this respect, $S$. isovalerica resembles other free-living anaerobic and facultatively anaerobic spirochetes that have been described (4, 8 ). Even when leucine, isoleucine, and valine were supplied in combination with other amino acids or organic acids, they did not support the growth of $S$. isovalerica.

Effect of salt on the growth of $S$. isovalerica. $S$. isovalerica strain $\mathrm{MA}-2^{\mathrm{T}}$ grew optimally in MMM broth containing between 200 and 300 $\mathrm{mM} \mathrm{NaCl}$. The four $S$. isovalerica strains failed to grow in $\mathrm{MMM}$ broth lacking $\mathrm{NaCl} . \mathrm{NaCl}$ could not be replaced by $\mathrm{KCl}$ in $\mathrm{MMM}$ broth. Thus, the $S$. isovalerica strains had a specific requirement for relatively high concentrations of $\mathrm{Na}^{+}$. On the basis of this requirement, we concluded that $S$. isovalerica is a marine bacterial species (14). The yields of $S$. isovalerica cells growing in MMM broth were reduced significantly when $\mathrm{MgSO}_{4}$ was omitted from this medium, and strains MA-2 ${ }^{\mathrm{T}}, \mathrm{MA}-3$, and RB-2 failed to grow when $\mathrm{CaCl}_{2}$ was omitted from MMM

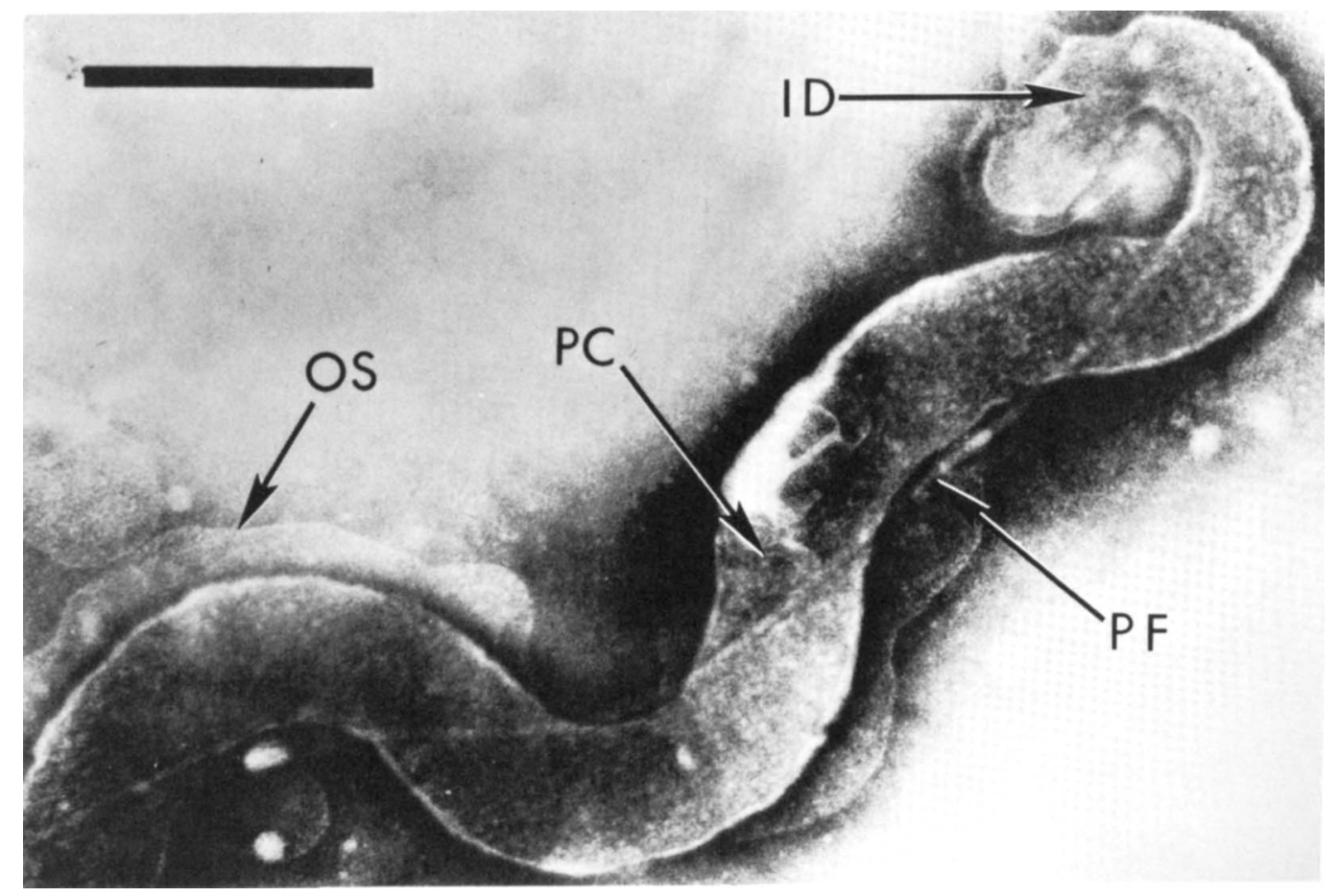

FIG. 2. Electron micrograph of one end of a negatively stained cell of $S$. isovalerica MA- $2^{\mathrm{T}}$. A periplasmic fibril (PF) is anchored by an insertion disk (ID) and is wound around the protoplasmic cylinder (PC). The outer sheath (OS) appears to surround both the periplasmic fibril and the protoplasmic cylinder. Bar $=1 \mu \mathrm{m}$. 
broth. Strain WH-2 grew slightly in MMM broth lacking $\mathrm{CaCl}_{2}$. Thus, $S$. isovalerica resembles other marine bacteria that have been examined with respect to the divalent ions $\mathrm{Ca}^{2+}$ and $\mathrm{Mg}^{2+}$, which are required for optimal growth in addition to $\mathrm{Na}^{+}$(17).

Fermentation products. The major fermentation products formed by $S$. isovalerica strains growing in MSM broth were ethanol, acetate, $\mathrm{H}_{2}$, and $\mathrm{CO}_{2}$. Significant amounts of the branched-chain fatty acids isovalerate, 2-methylbutyrate, and isobutyrate were also produced by each $S$. isovalerica strain. In addition, smaller quantities of isobutanol and isoamyl alcohol were formed. We have shown previously that ethanol, acetate, $\mathrm{H}_{2}$, and $\mathrm{CO}_{2}$ are products of glucose fermentation by $S$. isovalerica $\mathrm{MA}-2^{\mathrm{T}}$ (9). We have also determined that this strain ferments L-leucine, $\mathrm{L}$-isoleucine, and L-valine to form isovalerate, 2-methylbutyrate, and isobutyrate, respectively (9). Isobutanol and isoamyl alcohol are also derived from the metabolism of the above-mentioned branched-chain amino acids. Quantitative data on the relative amounts of fermentation products formed by $S$. isovalerica MA- $2^{\mathrm{T}}$ under a variety of growth conditions have been published elsewhere (9). The $S$. isovalerica strains did not form succinate, fumarate, oxaloacetate, formate, butyrate, propionate, valerate, acetoin, 2,3-butanediol, or diacetyl as fermentation products. A small amount of lactate was produced by $S$. isovalerica $\mathrm{MA}-2^{\mathrm{T}}$ but not by the other $S$. isovalerica strains.

Enzyme activities typical of the EmbdenMeyerhof and hexose monophosphate pathways were detected in $S$. isovalerica MA- $2^{\mathrm{T}}$ cell extracts (Table 1). 6-Phosphogluconate dehydratase and 2-keto-3-deoxy-6-phosphogluconate aldolase, enzyme activities typical of the EntnerDoudoroff pathway, were not detected in cell extracts. Cell extracts of $S$. isovalerica MA- $2^{\mathrm{T}}$ also contained four enzymatic activities necessary to convert the amino acids L-leucine, Lisoleucine, and L-valine to their corresponding branched-chain fatty acid fermentation products; these activities were amino acid aminotransferase, 2-keto acid oxidoreductase, phosphate acyltransferase, and fatty acid kinase (10).

DNA base composition. Determinations of melting temperatures indicated that the $\mathrm{G}+\mathrm{C}$ contents of the DNAs of $S$. isovalerica strains WH-2, MA-3, MA- ${ }^{\mathrm{T}}$, and RB-2 were 63.6, 64.1, 64.5 , and $65.6 \mathrm{~mol} \%$, respectively.

\section{DISCUSSION}

Free-living spirochetes that are capable of anaerobic growth are classified in the genus Spirochaeta (3). Thus, strains MA-2 ${ }^{\mathrm{T}}$, MA-3, WH-2, and RB-2 are appropriately assigned to
TABLE 1. Enzymatic activities in cell extracts of $S$. isovalerica $\mathrm{MA}-2^{\mathrm{T}}$

\begin{tabular}{lr}
\hline Enzyme & Sp act $^{a}$ \\
\hline Phosphofructokinase $\ldots \ldots \ldots \ldots \ldots \ldots \ldots$ & 1.5 \\
Fructose diphosphate aldolase $\ldots \ldots \ldots \ldots \ldots$ & 57.4 \\
Glyceraldehyde phosphate dehydrogenase $\ldots$ & 540.0 \\
Glucose-6-phosphate dehydrogenase $\ldots \ldots \ldots \ldots$ & 6.1 \\
Phosphogluconate dehydrogenase $\ldots \ldots \ldots \ldots$ & 22.2 \\
\hline
\end{tabular}

${ }^{a}$ Expressed as nanomoles of pyridine nucleotide reduced per minute per milligram of protein.

this genus. The four strains of marine spirochetes described in this paper are obligately anaerobic and on this basis are clearly different from Spirochaeta halophila and Spirochaeta aurantia, two facultatively anaerobic Spirochaeta species. The marine strains which we studied differ in salt requirement and in a number of other characteristics from Spirochaeta stenostrepta and Spirochaeta zuelzerae, two obligately anaerobic species that were isolated from freshwater environments $(3,4)$. With respect to their major fermentation products and their requirements for $\mathrm{Na}^{+}$ions, the four strains which we studied appear to be most similar to the marine organism Spirochaeta litoralis. However, the marine strains described in this paper can be clearly differentiated from $S$. litoralis by their ability to ferment branched-chain amino acids and form minor amounts of branchedchain fatty acids. We have shown previously that branched-chain fatty acid formation by strain MA- $2^{\mathrm{T}}$ involves four enzymatic steps (10). $S$. litoralis appears to lack the genetic information required to code for the proteins that mediate these enzymatic reactions. In addition, $S$. litoralis differs from strains MA- ${ }^{\mathrm{T}}, \mathrm{MA}-3, \mathrm{WH}-$ 2 , and RB-2 in morphology, in growth substrate utilization, and in DNA G+C content (Table 2). In view of these findings, we concluded that the marine isolates described in this paper represent a new species, for which we propose the name Spirochaeta isovalerica.

Our data show that $S$. isovalerica is a saccharolytic species that does not utilize amino acids or most organic acids as growth substrates. Previously, we have shown that $S$. isovalerica MA $-2^{\mathrm{T}}$ ferments L-leucine, L-isoleucine, and Lvaline and forms isovalerate, 2-methylbutyrate, and isobutyrate, respectively, as end products (9) and that it utilizes the adenosine $5^{\prime}$-triphosphate generated from these fermentations for cell functions not related to growth (9). It seems likely that these conclusions also apply to the other strains of $S$. isovalerica. Using procedures in which rifampin was the selective agent (19) and other selective procedures, we have been unable to obtain marine spirochetes that are able 
TABLE 2. Characteristics that distinguish $S$. isovalerica from $S$. litoralis ${ }^{a}$

\begin{tabular}{|c|c|c|c|c|c|c|c|c|c|c|}
\hline \multirow[b]{2}{*}{ Species } & \multicolumn{3}{|c|}{ Cell morphology } & \multirow{2}{*}{$\begin{array}{l}\text { Growth factors } \\
\text { required }\end{array}$} & \multirow{2}{*}{$\begin{array}{c}\text { Branched-chain fatty } \\
\text { acid fermentation } \\
\text { products }^{b}\end{array}$} & \multicolumn{4}{|c|}{ Utilization of: } & \multirow{2}{*}{$\begin{array}{c}\mathrm{G}+\mathrm{C} \\
\text { content } \\
(\mathrm{mol} \%)^{d}\end{array}$} \\
\hline & Shape & $\begin{array}{l}\text { Width } \\
(\mu \mathrm{m})\end{array}$ & $\begin{array}{c}\text { Length } \\
(\mu \mathrm{m})\end{array}$ & & & $\begin{array}{l}\text { Raffi- } \\
\text { nose }\end{array}$ & $\begin{array}{c}\text { Manni- } \\
\text { tol }\end{array}$ & $\begin{array}{l}\text { Lac- } \\
\text { tose }\end{array}$ & $\begin{array}{l}\text { Inu- } \\
\text { lin }\end{array}$ & \\
\hline S. isovalerica & Helical & 0.4 & $10-15$ & None & $\begin{array}{l}\text { Isovalerate, } 2- \\
\text { methylbutyrate, } \\
\text { isobutyrate }\end{array}$ & - & + & - & - & $63.6-65.6$ \\
\hline$S$. litoralis & Helical & $0.4-0.5$ & $5.5-7.0$ & $\begin{array}{r}\text { Biotin, niacin, } \\
\text { coenzyme A }\end{array}$ & None & + & - & + & + & $44.2^{e}$ \\
\hline
\end{tabular}

${ }^{a}$ Data are from this study and reference 12 .

${ }^{b}$ Determined by using cultures grown in MSM broth in this study.

${ }^{c}+$, All strains positive for utilization of the compound as a sole carbon and energy source; - , all strains negative.

${ }^{i}$ Determined by the thermal denaturation method.

${ }^{e}$ Data from reference 2 .

to utilize amino acids as sole carbon and energy sources for growth.

Description of Spirochaeta isovalerica sp. nov. S. isovalerica (i.so.val.er'ic.a. M.L. fem. adj. isovalerica of isovaleric acid, the major acid formed as a fermentation product from branched-chain amino aids) cells are helical and 0.4 by 10 to $15 \mu \mathrm{m}$. Shorter $(6 \mu \mathrm{m})$ and longer (up to $50 \mu \mathrm{m}$ ) cells occur in cultures. Motile. Two subterminally inserted periplasmic (axial) fibrils are present in a 1-2-1 arrangement. The protoplasmic cylinder and periplasmic fibrils are enclosed in an outer sheath. Gram negative.

Chemoorganotrophic. Grows (final yield, $6 \times$ $10^{8}$ to $9 \times 10^{8}$ cells per $\mathrm{ml}$ ) in medium containing yeast extract, Trypticase, peptone, a carbohydrate, and inorganic salts under anaerobic conditions (in an $\mathrm{N}_{2}$ atmosphere). No growth occurs aerobically. Subsurface colonies in medium containing $0.8 \%$ agar (Difco) are spherical and white, resembling cotton balls in appearance. Growth (final yield, $3 \times 10^{8}$ to $6 \times 10^{8}$ cells per $\mathrm{ml}$ ) occurs in a chemically defined medium containing glucose, cysteine or sulfide, asparagine, vitamins, $0.3 \mathrm{M} \mathrm{NaCl}, 0.05 \mathrm{M} \mathrm{MgSO}_{4}, 0.01 \mathrm{M}$ $\mathrm{KCl}, 0.01 \mathrm{M} \mathrm{CaCl}_{2}$, and trace elements. Exogenously supplied vitamins are not required for growth, but a mixture of vitamins stimulates growth. Fails to grow when $\mathrm{NaCl}$ is omitted from the medium. Growth is stimulated by $\mathrm{MgSO}_{4}$ and $\mathrm{CaCl}_{2}$. Inorganic ammonium salts or amino acids serve as nitrogen sources. Carbohydrates, but not amino acids, serve as carbon and energy sources for growth.

The major products of glucose fermentation are $\mathrm{H}_{2}, \mathrm{CO}_{2}$, acetate, and ethanol. Cells have the ability to generate adenosine 5 '-triphosphate by catabolizing L-leucine, L-isoleucine, and Lvaline to form isovalerate, 2-methylbutyrate, and isobutyrate, respectively, as end products. Adenosine 5 -triphosphate formed in this way is utilized by cells to prolong survival during periods of growth substrate starvation. Smaller amounts of isobutanol and isoamyl alcohol are also formed by cells from valine, isoleucine, and leucine.

Catalase negative; nitrate not reduced to nitrite. Optimum temperature range, 15 to $35^{\circ} \mathrm{C}$. Poor growth at 5 and $39^{\circ} \mathrm{C}$. The $\mathrm{G}+\mathrm{C}$ content of the DNA is 63.6 to $65.6 \mathrm{~mol} \%$, as determined by thermal denaturation. Isolated from anoxic marine marsh mud. The type strain is MA-2; this strain has been deposited with the German Collection of Microorganisms, Göttingen, Federal Repubic of Germany, under the number DSM 2461.

\section{ACKNOWLEDGMENTS}

We thank B. J. Paster for the electron micrograph.

This research was supported by Public Health Service grant AI-17737 from the National Institute of Allergy and Infectious Diseases. C.S.H. was the recipient of a National Institutes of Health Research Service Award under Public Health Service grant GM-07473 from the National Institute of General Medical Sciences.

\section{LITERATURE CITED}

1. Blakemore, R. P., and E. Canale-Parola. 1973. Morphological and ecological characteristics of Spirochaeta plicatilis. Arch. Mikrobiol. 89:273-289.

2. Breznak, J. A., and E. Canale-Parola. 1975. Morphology and physiology of Spirochaeta aurantia strains isolated from aquatic habitats. Arch. Microbiol. 105:1-12.

3. Canale-Parola, E. 1974. Genus I. Spirochaeta Ehrenberg 1835, 313, p. 168-171. In R. E. Buchanan and N. E. Gibbons (ed.), Bergey's manual of determinative bacteriology, 8th ed. the Williams \& Wilkins Co., Baltimore.

4. Canale-Parola, E. 1977. Physiology and evolution of spirochetes. Bacteriol. Rev. 41:181-204.

5. Canale-Parola, E. 1978. Motility and chemotaxis of spirochetes. Annu. Rev. Microbiol. 32:69-99.

6. Canale-Parola, E., S. C. Holt, and Z. Udris. 1967. Isolation of free-living anaerobic spirochetes. Arch. Mikrobiol. 59:41-48.

7. Canale-Parola, E., Z. Udris, and M. Mandel. 1968. The classification of free-living spirochetes. Arch. Mikrobiol. 63:385-397.

8. Greenberg, E. P., and E. Canale-Parola. 1976. Spirochaeta halophila sp. n., a facultative anaerobe from a high-salinity pond. Arch. Microbiol. 110:185-194.

9. Harwood, C. S., and E. Canale-Parola. 1981. Branchedchain amino acid fermentation by a marine spirochete: 
strategy for starvation survival. J. Bacteriol. 148:109-116.

10. Harwood, C. S., and E. Canale-Parola. 1981. Adenosine 5 '-triphosphate-yielding pathways of branched-chain amino acid fermentation by a marine spirochete. J. Bacteriol. 148:117-123.

11. Harwood, C. S., and E. Canale-Parola. 1982. Properties of acetate kinase isozymes and a branched-chain fatty acid kinase from a spirochete. J. Bacteriol. 152:246-254.

12. Hespell, R. B., and E. Canale-Parola. 1970. Spirochaeta litoralis sp. n., a strictly anaerobic marine spirochete. Arch. Mikrobiol. 74:1-18.

13. Hespell, R. B., and E. Canale-Parola. 1970. Carbohydrate metabolism in Spirochaeta stenostrepta. J. Bacteriol. 103:216-226.

14. MacLeod, R. A. 1965 . The question of the existence of specific marine bacteria. Bacteriol. Rev. 29:9-23.

15. Mandel, M., and J. Marmur. 1968. Use of ultraviolet absorbance-temperature profile for determining the guanine plus cytosine content of DNA. Methods Enzymol. 12B:195-206.

16. Paster, B. J., and E. Canale-Parola. 1982. Physiological diversity of rumen spirochetes. Appl. Environ. Microbiol. 43:686-693.

17. Reichelt, J. L., and P. Baumann. 1974. Effect of sodium chloride on growth of heterotrophic marine bacteria. Arch. Microbiol. 97:329-345.

18. Smibert, R. M., and N. R. Krieg. 1981. General characterization, p. 409-443. In P. Gerhardt et. al. (ed.), Manual of methods for general bacteriology. American Society for Microbiology, Washington, D.C.

19. Weber, F. H., and E. P. Greenberg. 1981. Rifampin as a selective agent for the enumeration and isolation of spirochetes from salt marsh habitats. Curr. Microbiol. 5:303306. 